\title{
Commission 38 (Exchange of astronomers) and Commission 46 (Teaching of astronomy): two commissions that played a unique role in the history and development of the IAU
}

\author{
John B. Hearnshaw \\ Department of Physics and Astronomy, \\ University of Canterbury, Christchurch, New Zealand \\ email: john.hearnshaw@canterbury.ac.nz
}

\begin{abstract}
The founding and development of two commissions of the IAU that played a unique role in IAU history are traced. Commission 38 for the Exchange of astronomers was founded in 1946 with Frederick Stratton as first president, and it expended funds (initially granted by UNESCO) for astronomers to travel on exchange visits. Commission 46 for the Teaching of astronomy was founded in 1964 with Evry Schatzmann as first president. This was a time of rapidly growing interest in the IAU for teaching astronomy and in due course for promoting astronomy in developing countries. For a while, both commissions operated under the wing of the Executive Committee. Their role was unique as they were the only IAU commissions to have their own budget, as well as aspiring to bring about social change in the astronomical community. By 2000 both commissions merged into C46 (Astronomy education and development) and by that time various programmes such as the International School for Young Astronomers (ISYA), the working group World-wide Development of Astronomy (WWDA) and the working group Teaching Astronomy for Development (TAD), which grew out of the Visiting Lecturers' Program (VLP), were all run by C46. When the IAU established the Office of Astronomy for Development in 2011, many of these functions were removed from the commission and in any case C46 ceased to exist in 2015 when all the old commissions were disestablished. In 2015 the Office for Young Astronomers took over the running of the ISYA. The history of C38 and C46 represents a time of active change in the way the IAU was engaging with people. It was more than just a union for scientific research, but in the world of scientific unions, it was remarkable for taking an active hands-on role in implementing social change. In the history of these two commissions, the Swiss astronomer Edith Müller played a leading dynamic role. She served as president of C46 (1967-73), of C38 (1985-88) as well as IAU General Secretary (1976-79).
\end{abstract}

Keywords. Exchange of astronomers, teaching of astronomy, astronomy in developing countries

\section{Introduction}

Commission 38 (Exchange of astronomers) and Commission 46 (Teaching of astronomy) played a unique role in the history and development of the IAU. These were the only commissions not to be concerned with the coordination of scientific research in astronomy, but to be engaged with promoting social change in the astronomical community. Also, they were the only commissions to receive direct funding from the IAU Executive Committee. This talk reviews the formation and activities of these two commissions. Some of the successes and problems are highlighted and some of the key personailities involved are mentioned. Eventually C38 and C46 merged into one commission in 2000, which lasted a further 15 years until all the old commisions were disestablished in 2015 . 
The work of these commissions at different times in their history provides a snapshot of how the IAU iteself was evolving in its mission, from an organization that was inward-looking and involved with purely scientific matters, such as uniform standards and classification schemes, to one increasingly involved with people - not only with professional astronomers, but also with students and eventually with the general public.

\section{Commision 38: Exchange of astronomers}

At the Meeting of the IAU Executive Committee (Copenhagen, March 1946) it was resolved (Stratton 1950):

(a) 'That a standing Commission be appointed for facilitating the exchange of astronomers.

(b) That the attention of U.N.E.S.C.O. be drawn to the existence of this Commission as an advisory body to whom U.N.E.S.C.O. could refer questions of the exchange of astronomers.'

The first post-war General Assembly was in Zürich in 1948 when the new commission was established with Frederick Stratton (UK) as the first president. Stratton had sent a questionnaire to a large number of observatories to inquire about: (1) possible assistantships or research fellowships available for astronomers of other countries; and (2) known cases where students had been prevented from working at a foreign observatory owing to currency restriction, or the lack of the necessary funds. At the same time particulars were asked as to foreign astronomers who had worked at the observatories in recent years. The replies showed that over fifty astronomers had actually been working abroad from their own countries in recent years of whom over twenty had been working in war or recent post-war years.

Even before the Zürich GA, eight grants for travel were awarded to facilitate the exchange of astronomers. Funding in these early years came from UNESCO with grants to the IAU of $\$ 2000$ in 1947 , increasing to $\$ 3000$ in 1948 . These initial grants helped with travel expenses, but not living costs abroad. For these first grants, four were for exchanges within Europe, two were from Europe to the US and two were from China to Europe or the US. Grants were for travel by young early-career astronomers as well as for senior astronomers going to less developed countries. A typical visit was for three months or longer.

\subsection{Cost of the Exchange of Astronomers programme}

Information on the cost of the Exchange of Astronomers programme can be obtained from the rather fragmented information in the commission reports. Most of the funding came from the IAU itself, and IAU support went from $\$ 4000$ p.a. in 1950 to $\$ 6000$ p.a. in 1958 , to $\$ 7500$ p.a. in 1961 . For $1966-69$, grants made totalled $\$ 24741$. By 1970 the Executive Committee approved $\$ 22000$ for the triennium 1970-73. In addition, ICSU granted \$4000. For 1991-94, the funding of C38 was CHF 76000 (about $\$ 57000$ ); for 1994-97 it was CHF 88000 (about $\$ 59000$ ). The grants totalled about CHF 25000 p.a. in 2000 (about $\$ 14500$ p.a.). In 2003 the average grant was a little under $\$ 2000$.

\subsection{Numbers of grants awarded in the Exchange of Astronomers programme}

The popularity of C38 grants can be judged by the growth of the Exchange of Astronomers programme over the first two decades of its operation. At first between five and ten awards were made annually, but this grew to about 15 to 20 awards in the 1960s. By 2009, after 63 years of the Exchange of Astronomers programme, there 
Table 1. C38 grants awarded

\begin{tabular}{|c|c|c||c|c|c|}
\hline Years & Grants & Total & Years & Grants & Total \\
\hline $1947-50$ & 22 & 22 & $1978-81$ & 24 & 337 \\
$1951-54$ & 17 & 39 & $1981-84$ & 23 & 360 \\
$1955-58$ & 30 & 69 & $1984-87$ & 23 & 383 \\
$1958-61$ & 27 & 96 & $1987-90$ & 27 & 410 \\
$1961-64$ & 27 & 123 & $1991-93$ & 24 & 434 \\
$1964-67$ & 53 & 176 & $1993-96$ & 31 & 465 \\
$1967-69$ & 41 & 217 & $1996-99$ & 35 & 500 \\
$1969-72$ & 57 & 274 & $1999-2002$ & 28 & 528 \\
$1972-75$ & 21 & 295 & $2003-06$ & 15 & 543 \\
$1975-78$ & 18 & 313 & $2006-09$ & 15 & 558 \\
\hline
\end{tabular}

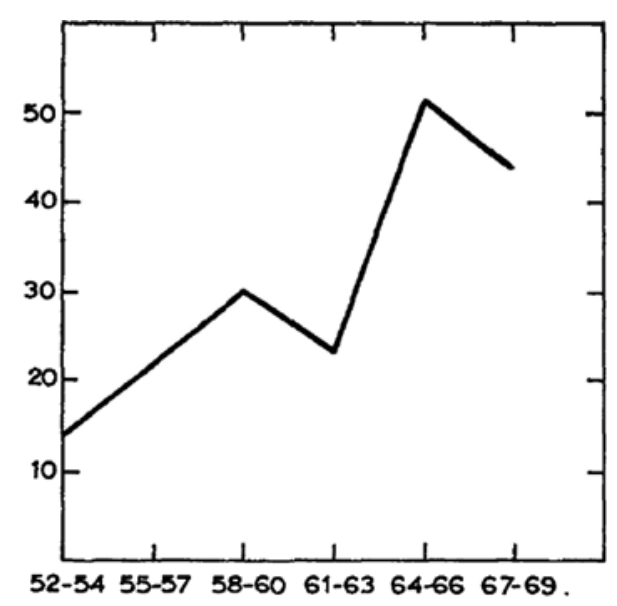

Figure 1. Growth of the number of C38 awards, 1952-69, from Minnaert (1970).

was a total of 558 grants made, or an average of about nine per year. The number of awards slowly declined from its height in the 1960s to be once again five to ten per year in the early years of the present century. The height of the C38 programme in the 1960s can be ascribed to the widespread availability of inexpensive air travel at that time. The decline towards the end of the programme is probably the result of alternative sources for the funding of scientific travel being available, often from within institutional budgets. Table 1 gives the numbers of grants awarded in 63 years of the programme.

The great majority of the awardees were early-career astronomers and often from developing countries. From the 1960s the commission published the names of those receiving grants for research visits, and a number of future famous astronomers feature; thus the 1970 report has the names of K. C. Freeman (travel from Austin, TX to London), M. J. Rees (Cambridge, UK to Pasadena) and F. Pacini (Rome to Ithaca, NY) (Minnaert 1970).

Fig. 1 is a plot published by Minnaert (1970) showing the growth of the number of C38 awards over the years 1952-69.

\subsection{The C38 presidents}

The IAU is fortunate that many distinguished astronomers were willing to work for Commission 38 as commission president. Evidently serving the commission entailed a certain kudos and prestige, so some of the community's best known astronomers have served in this capacity. During the life of Commission 38 from 1948 to 2000, there were 12 presidents, and for the following nine years there were three chairs of the Exchange 


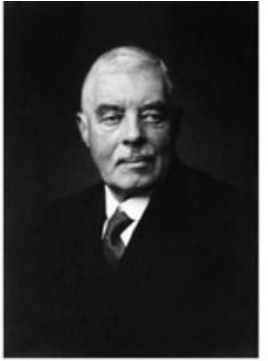

FJM Stratton UK 1948-60

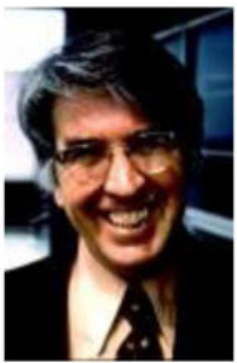

DA Macrae

Canada

1976-79

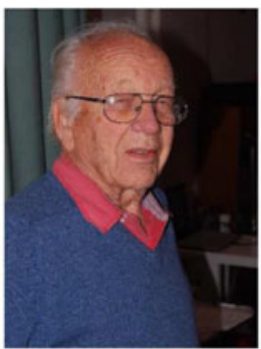

FG Smith

UK

1988-91

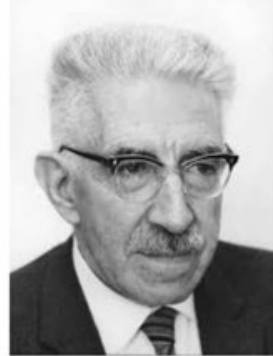

MGJ Minnaert

Netherlands

1961-70

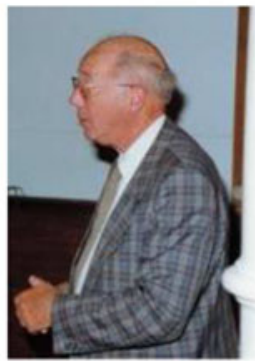

J Delhaye

France

1979-82

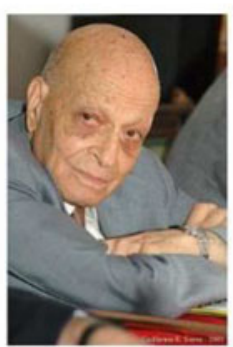

J Sahade

Argentina

1991-94

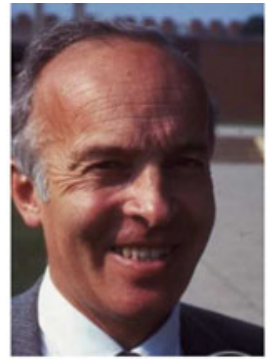

A Reiz

Denmark

1970-73

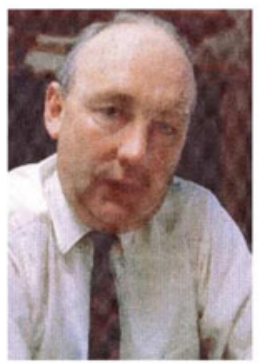

FB Wood

USA

1982-85

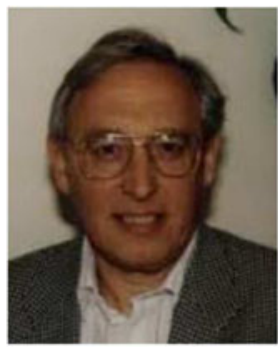

HE Jørgensen

Denmark

1994-97

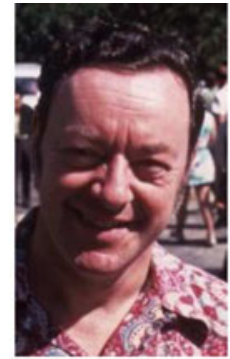

PM Routly

USA

1973-76

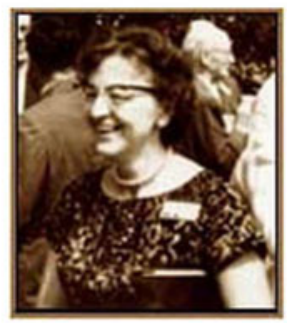

EA Müller

Switzerland

1985-88

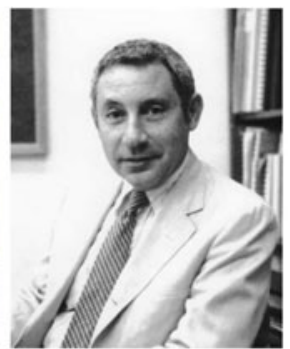

MS Roberts

USA

1997-2000

Figure 2. Presidents of Commission 38, 1948-2000.

of Astronomers programme within Commission 46. Everyone of these 15 astronomers was distinguished and well-known for their reearch contributions. They are portrayed in Fig. 2 and in Fig. 3.

\subsection{The merger with $C 46$ and the demise of the Exchange of Astronomers program}

In 2000 at the Manchester IAU General Assembly, the Exchange of Astronomers commision became a program group $(\mathrm{PG})$ of Commission 46 (now renamed Astronomy Education and Development). As a result, Commission 38 was disbanded. A chair was appointed to run the new PG, and ostensibly the operation continued as before. However, the number of grants awarded began to decline from the turn of the century, not necessarily because of the merger, but more probably because of the relative cheapness of air travel and the availability of funds from alternative sources, including 


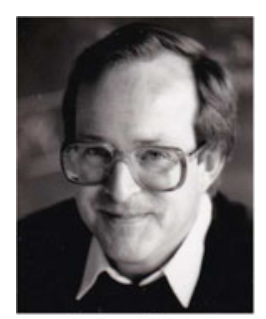

Richard West

Denmark

2000-03

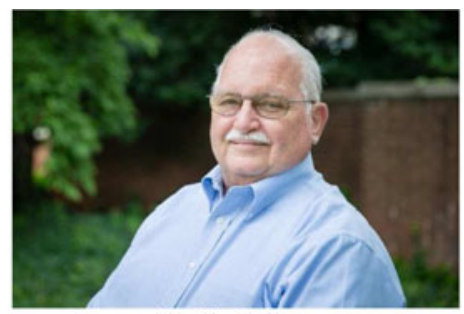

Charlie Tolbert

USA

2003-06

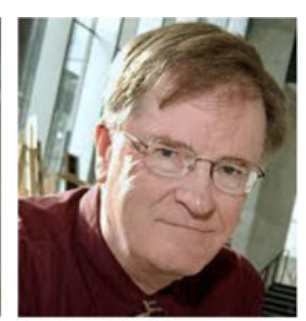

John Percy

Canada

2006-09

Figure 3. Exchange of Astronomers Program Group chairs, 2000-09.

institutional budgets. In its final years, an average of just five awards a year were being made.

A major aim of Commission 38 had been to help astronomers in developing countries. In 2010 the IAU created the Office of Astronomy for Development in Cape Town, and from this time all the IAU support for astronomy as a tool for development was chanelled through that office. All the old commissions, including C46, ceased to exist in 2015. None of the new commissions created in 2015 had direct IAU funding or a budget. This was therefore the end of an era for the IAU's development programme based on its commisions.

\section{Commision 46: The teaching of astronomy}

A new IAU commission was created in 1964 at the Hamburg General Assembly - it was Commission 46: The Teaching of Astronomy. This was largely on the initiative of Marcel Minnaert, the C38 president, and of Jean-Claude Pecker (Fig. 4), the IAU General Secretary. Evry Schatzman (France) was the first C46 president (1964-67). This was an important milestone for the IAU, as it marked the first real involvement of the Union in astronomy education.

The Hamburg General Assembly marked this occasion with a 1-day meeting on the teaching of astronomy. The workshop covered the training of PhD students, and young astronomer career paths, the syllabus of university astronomy courses, international cooperation in teaching, laboratory exercises in astronomy and the need to teach the new science of radio-astronomy. The teaching of astronomy in secondary schools was also discussed.

At this workshop, Minnaert commented:

'There is hardly any other science which gives such an enlightenment of the mind within such a short time. The interest of the pupils for astronomy is spontaneous and very general, and schools should take advantage of this interest' (Minnaert 1966).

The first International School for Young Astronomers (at the time called 'Summer School for Young Astronomers') was held in Manchester, UK, in 1967 under the auspices of Commission 46. Further schools were held in Arcetri, Italy in 1968 and in Hyderabad, India in 1969. They became regular events, mainly held annually, and they were a flagship activity of Commission 46. Josip Kleczek (Czechoslovakia; Fig. 5) was ISYA secretary for the first 18 schools (until 1991) and the person who shaped their initial success.

\subsection{Notable $C_{4} 6$ events and developments}

The new commission was almost immediately full of plans for new activities to promote astronomy education. In 1970, the second C46 president Edith Müller introduced 


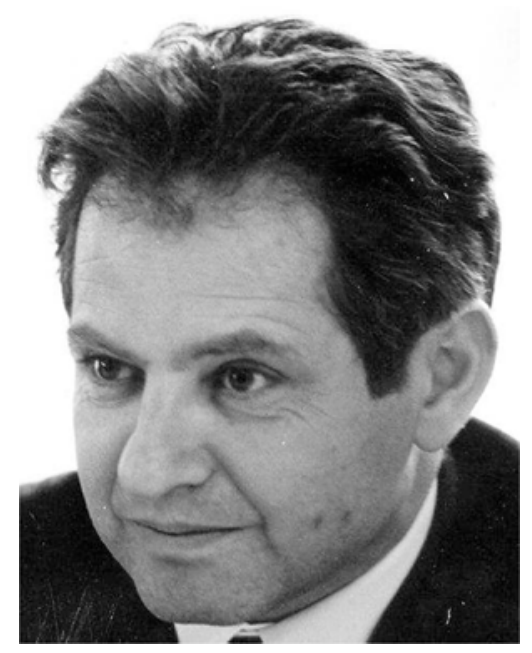

Figure 4. Jean-Claude Pecker, who was IAU General Secretary 1964-67, and one of the architects of Commission 46 for the Teaching of Astronomy.

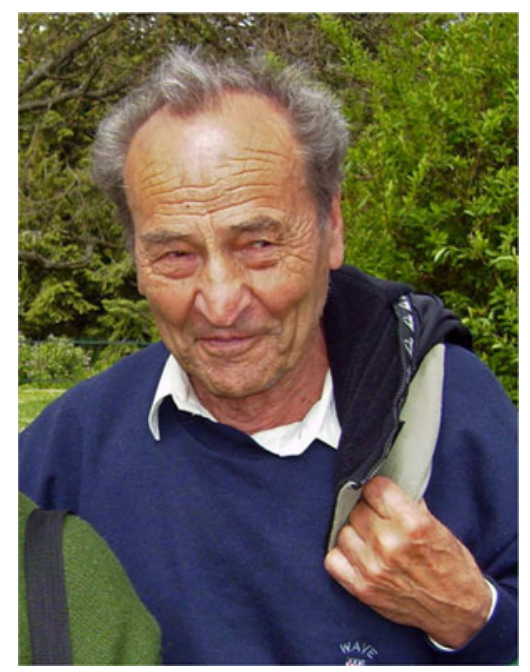

Figure 5. Josip Kleczek, Czechoslovakia, was the secretary for ISYA and shaped the whole ISYA programme from 1967 to 1991.

the concept of National Liaisons in astronomy education. The proposal was to identify astronomers in each IAU member country who would write triennial reports on educational developments in astronomy in their country. By 1973, after the first triennium of the scheme, 33 member countries had established a person to act as the National Liaison, and 17 of these countries had sent in reports covering astronomy education from primary to tertiary level (Müller 1973). In 1982 the number of countries with liaisons had grown to 46 (Wentzel 1982).

Also in 1970 Michèle Gerbaldi in Paris started the 'Contratype' project to duplicate slides, videos and images to distribute for astronomy education (CP). By 1976, 32 orders for slide sets had been processed, coming from both universities and school teachers (McNally 1977). In 1982 Gerbaldi reported that the distribution of slide sets and posters had been made to seven countries, supported by the VM Slipher Fund of the US 
National Academy of Sciences, and the circulation of six NASA movies had been made to 14 countries (Wentzel 1982).

Another initiative was the Astronomy Educational Materials (AEM) project, which published long lists of educational materials, such as books, articles, images, exercises etc. This started in 1973 .

Also in 1973 the Visiting Lecturers Project (VLP) was proposed, in which visiting lecturers would be sent to developing countries to teach astronomy courses at university level. $\$ 6000$ over three years was requested from IAU Executive Committee. But it was not funded until the 1980s, and then only poorly. (VLP was also sometimes referred to as the Visiting Professors' Project.)

In 1976 the C46 Newsletter was launched with Derek McNally (UK) as the first editor. The C46 Newsletter was published twice a year and the first issue appeared in January 1977. McNally served as C46 vice-president from 1970 and as president for the triennium starting in 1973.

In 1976 McNally proposed establishing an International Institute of Astronomy for research, training of teachers and education, possibly modelled on the International Centre for Theoretical Physics in Trieste, Italy, which had been founded by Abdus Salam in 1964 with the support of UNESCO. Unfortunately the proposal for an international astronomical institute came to nought.

Extensive Rules and Guidelines for Commission 46 were published by McNally in 1976 (McNally 1976). The objectives were declared to be 'to further the development and improvement of astronomical education at all levels throughout the world'. The composition and role of the Commission's organizing committee were spelt out here.

In 1979 the fourth C46 president, Edward Kononovich from the Soviet Union, stressed 'the contradiction between fundamental importance of astronomy to human progress and its poor representation in the world educational system' (Kononovich 1979). He also pointed out that a shortage of funding was the main obstacle that hampered the work of the commission.

In August 1979, Kononovich (1979) reported that a Working Group was formed to discuss the Education of Astronomers in Developing Countries. Sylvio Ferraz-Mello from Brazil was appointed the chair and there were six further members, two of them from Commission 38. The Working Group reported three years later at the Patras, Greece, General Assembly with the recommendation to the Executive Committee that $\$ 17000$ be expended in the coming triennium to support the Visitng Lecturers' Program (VLP) in developing countries (Wentzel 1982). The VLP did not fluorish in the coming years, even though the funding request was approved at the Patras General Assembly.

In 1979 both Commisions 38 and 46 became committees of the IAU's Executive Committee. Presumably this development was to give tighter control of the funding, given that these were the only commissions to incur expenditure.

A new initiative, the Travelling Telescope (TT) project was launched by Derek McNally and Richard West in 1984 for Commission 46. John Percy obtained UNESCO funds for TT in 1988 to purchase a Celesctron C8 Schmidt-Cassegrain telescope with a photometer and spectrograph for education in developing countries. Although it was a great idea in principle, the TT project never really thrived because of the expense of shipping the gear to distant countries and the need for supervision while overseas and for maintenance on the telescope's return.

Other activities delivered a more immediate reward, including IAU Colloquium no. 105 on the Teaching of Astronomy. This was held at Williams College in Massachusetts in 1988, and represented the first IAU conference on this subject. The editors of the proceedings were Jay Pasachoff and John Percy. There were 162 participants from 31 countries (Pasachoff \& Percy 1990). 
At the 1988 IAU General Assembly in Baltimore USA, a special session for school teachers was held with 80 teachers and 20 astronomers, under the auspices of Commission 46 . This successful meeting became a regular feature of future General Assemblies.

\subsection{Comments on C46's effectiveness in the early years}

Undoubtedly the greatest success of the Commission was ISYA, the International School for Young Astronomers. Eighteen schools were held during the years 1967-91 on four different continents, all under Josip Kleczek as secretary. UNESCO helped with some of the funding. ISYA were an immediate success, and they have continued to the present day as flagship activities of the IAU and Commission 46, both for the education of young astronomers as well as (except for the first few schools) a way of promoting astronomy in developing countries.

Another success was the Commission newsletter. By 1991 the C46 Newsletter had published 33 issues, with John Percy (Canada) as the editor following McNally. The Newsletter continues to this day, with Percy, Barrie Jones (UK) and Larry Marschall (US) as successive editors, with issue number 87 appearing in May 2018. It is a well-respected publication.

The Contratype project to duplicate slides had some success; there were 32 orders for slides in triennium 1973-76, but it did not survive more than a few years. With the instant availability of images over the internet, such a project would have no place in the modern digital world.

The Visiting Lecturers' Project (VLP) was never very successful; Jorge Sahade (Argentina) went to Paraguay and Peru to lecture during 1985-93. But a lack of funding continuously plagued the project. As for the Travelling Telescope (TT) project, it proved very expensive to ship $300 \mathrm{~kg}$ of crates around the world. The telescope went to Malaysia for ISYA in 1990; the photometer and spectrograph, but not the telescope, went to Paraguay for the VLP in 1992-93. Overall the programme was largely a failure.

The Astronomy Educational Materials project (AEM) started in 1970 but had stopped by 1994. The lists of material were long and unwieldy and published in four languages. Compiling these lists was labour-intensive, and there simply was not enough evidence that teachers needed such comprehensive lists of every resource that might be available.

National Liaisons were partially successful. For example, by 198841 countries had National Liaisons, but only 28 reports were received. These reports possibly provided interesting reading to see what was happening in different countries, but they were probably not fundamental drivers of change in any country.

School-teacher meetings at General Assemblies were well supported; for example there were 180 participants at the Hague General Assembly in 1994. Probably teachers gained more from this type of face-to-face interaction than from reading National Liaison reports.

The general comment can be made that although C38 and C46 were the only funded commissions of the IAU, many of the activities were poorly funded and they struggled to survive. That was certainly the view expressed by Edward Kononovich, when he wrote in 1979: 'The chief difficulty of the Commission work is the scarcity of funds' (Kononovich 1979). It can be summed up that activities which involved sending books, other material or equipment often floundered; those involving the interactions of people (such as meetings, exchanges, ISYA schools) were more successful.

\subsection{C46 events in later years (after 1994)}

In 1994, the Visiting Lecturers' Project (VLP) was renamed Teaching for Astronomy Development (TAD), a program group of Commission 46 under Donat Wentzel. It had some of the original VLP aims, but generally a broader mandate. TAD had close links to 
the Working Group for the World-wide Development of Astronomy (WGWWDA) which was also formed at this time under Alan Batten (Canada). WGWWDA was a working group of the Executive Committee, but initially was not directly linked to Commission 46. Some comments by John Percy on TAD and Commission 46 generally were published by Percy in a symposium proceedings on astronomy education sponsored by the Astronomical Society of the Pacific in 1994 (Percy 1996).

Education continued to play an important role in the IAU in the 1990s. There was a Joint Discussion (JD4) organized at the General Assembly in the Hague in 1994 on Astronomy Education. John Percy was the editor of the proceedings published in the Highlights of Astronomy (Percy 1995).

In 1997 a sub-committee of Commission 46 on solar eclipses for educational purposes was established with Jay Pasachoff as chair; also a sub-committee on the exchange of books and journals was set up (with D. Hoff as the chair).

Collaboration between Commission 46 and the UN Office for Outer Space Affairs (UNOOSA) (under Hans Haubold in Vienna) was started in 1997. UNOOSA was involved with space science education and ran workshops often in developing countries for students to gain a basic training in space science. A working group of C46 called the WG for Collaborative Programs was set up to coordinate such linkages with external agencies with a common interest in astronomy or space science education.

The second IAU Colloquium on astronomy teaching was held in London UK in 1996. Lucienne Gouguenheim (France), Derek McNally (UK) and John Percy (Canada) were the editors of the proceedings of IAU Colloquium No. 162 (Gouguenheim et al. 1998). Distance learning and use of the internet now became important aspects of astronomy teaching.

Meanwhile the program group Teaching for Astronomy Development (TAD) held a workshop for students in Vietnam at Vinh University in 1997, and another workshop in Nicaragua in 1999. The IAU was now reaching out more effectively to developing countries. This topic of how to promote astronomy in the developing world became an important one for the 2000 General Assembly in Manchester. The Working Group for the World-wide Development of Astronomy (WGWWDA) under Alan Batten held a special session on Astronomy for Developing Countries, with the proceedings volume published by the Astronomical Society of the Pacific, and edited by Batten (Batten 2001).

From the turn of the century, the commission became increasingly engaged with promoting astronomy in the developing world in addition to astronomy teaching. This led to the renaming of the commission in 2000 as C46: Astronomy Education and Development. A further development also occurred in 2000, when the commisssions C38 and C46 merged into an enlarged C46, which now also included Batten's WGWWDA, which was previously a separate working group under the Executive Committee. WGWWDA was briefly renamed the Advance Development Program Group (AD) in 2003.

In 2003 Commission 46 now had the following Program Groups: AD (Batten), TAD (Wentzel), CP (Collaborative Programs - Haubold), ISYA (Gerbaldi), Exchange of Astronomers (West), National Liaisons (Pasachoff), Newsletter (B. Jones), Education at the times of Solar eclipses (Pasachoff), Exchange of books and journals (D. Hoff). However, at the Sydney General Assembly in 2003, John Hearnshaw took over from Batten as $\mathrm{AD}$ chair, and immediately renamed this program group with the more descriptive name, the Program Group for the World-wide Development of Astronomy (PGWWDA). This name therefore closely resembled the former name of WGWWDA, when the group was under control of the Executive Committee. The group had about a dozen active members over the next several triennia and in this time Hearnshaw inititated an extensive programme of visits to developing countries by the 
members in order to give lectures on astronomy at universities and schools during visits which were typically of duration one to two weeks.

In 2006 a Special Session (SPS5) was organized by Hearnshaw at the Prague General Assembly on the topic 'Astronomy for the Developing World' (Hearnshaw and Martinez 2007).

In 2004-12, PGWWDA was active in Mongolia, Cuba, Trinidad \& Tobago, Thailand, Laos, Uzbekistan, Mauritius, Uruguay, Paraguay, Tajikistan, Fiji, DPR Korea, Mozambique, Ethiopia, Kazakhstan, Tunisia, Morocco, Cambodia, Burma, Brunei, Philippines, Bangladesh, Sri Lanka, Peru and Ecuador. In most years two or three visits were made by Hearnshaw or other group members.

In 2009 TAD (now run by Ed Guinan) reported being active in Kenya, DPRKorea (by correspondence), Mongolia, Morocco, Nicaragua, Philippines, Trinidad \& Tobago and Vietnam.

In 2012, Commission 46 established a new PG Network of Astronomy School Educators (NASE) to train school-teachers through workshops to teach astronomy. A series of workshops was started, at first operating in Latin America in Spanish, but later extending to the Middle East. Rosa Ros (Spain) with the assistance of Beatriz García (Argentina) were the chairs of NASE. By 2018, NASE had run 111 courses for teachers in 23 couuntries and their materials were translated and available in English, Spanish, Portuguese, Chinese Mandarin, Indonesian, Romanian and French, with preparations for translating into Japanese and Russian. This very successful program group therefore effectively combined the missions of astronomy education and promoting astronomy in developing countries.

\subsection{C46 (or C.C1) presidents, 1964-2018}

Commission 46 had 16 presidents over the period 1964 to 2015. All of them were very well-known astronomers who were also passionate about teaching and education. They brought about a social revolution in the way the IAU conducted itself, as the change from a purely scientific union to one that was concerned with how astronomy interacted and engaged with people was very much indicative of the role of this commission. All these presidents served for three-year terms except for Edith Müller (Switzerland), who served for a double triennium 1967-73. From 2015, Commission 46 was replaced by Commission $\mathrm{C} 1$ in the new IAU structure. It still had a mission and a president filling much the same role as before, but without the funding that $\mathrm{C} 46$ had enjoyed for half a century.

The presidents of C46 and C.C1 are shown in Figs. 6 and 7.

\subsection{The end of $\mathrm{C} 46$ as a funded commission for education and development}

In 2009 at the Rio de Janeiro General Assembly, the IAU adopted a Strategic Plan for 2010-20, following a Paris brainstorming workshop in January 2008 chaired by IAU vice-president George Miley (from the Netherlands). Also in 2009 the IAU created Division XII for union-wide activities and placed Commission 46 in this new division (instead of under the Executive Committee). The Strategic Plan included establishing the Office of Astronomy for Development (OAD) in Cape Town, with Kevin Govender as the first director. This was the first IAU office (other than the Paris Secretariat) with salried professional employees. Essentially all the funded activities of Commission 46 were transferred at this time to the new office, OAD.

In 2012 Commission 46 lost all its funded Program Groups, but nevertheless the commission remained very active in promoting astronomy education and development around the world. In 2012 the IAU created a new structure with nine divisions and three years later Commission 46 became C.C1 (Astronomy education and development) in Division C 


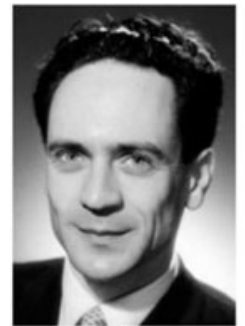

E Schatzman

France

1964-67

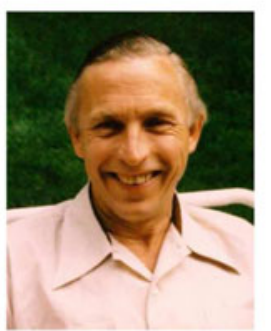

DG Wentzel

USA

1979-82

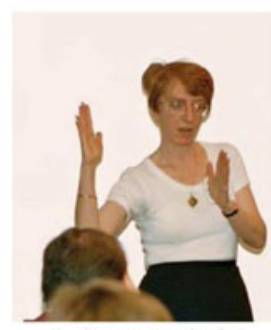

L Gouguenheim

France

1991-94

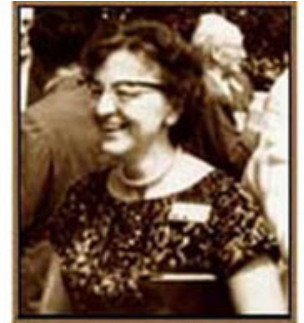

EA Müller

Switzerland

1967-73

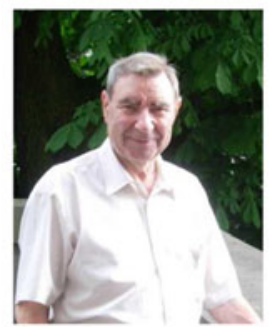

L Houziaux

Belgium

1982-85

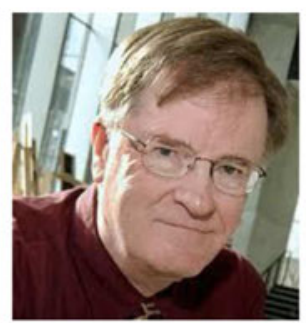

JR Percy

Canada

1994-97

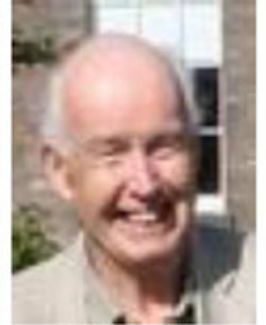

D McNally

UK

1973-76

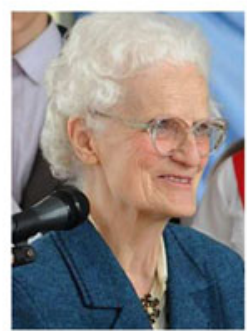

C Iwaniszewska

Poland

1985-88

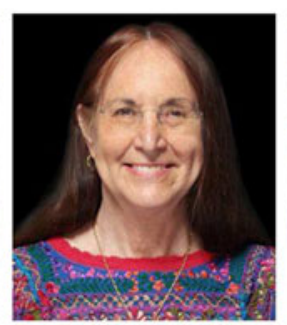

J Fierro

Mexico

1997-2000

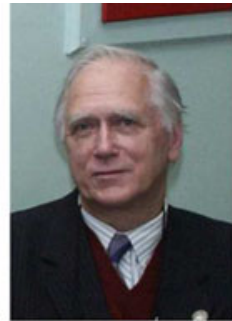

EV Kononovich

Soviet Union

1976-79

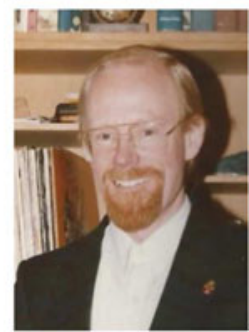

A Sandqvist

Sweden

1988-91

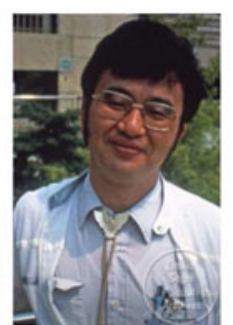

S Isobe

Japan

2000-03

Figure 6. Presidents of Commission 46, 1964-2003.

(Astronomy education, outreach and heritage). This therefore represented the end of one era, yet the start of a new one. For well over half a century the IAU had funded education, international collaboration and development of astronomy in developing countries through its two unique funded commisions, C38 and C46. The activities continued, but within a new structure and to some extent with new people leading the way forwards.

\subsection{The legacy of Commission 46}

Astronomy education has played a significant and growing role within the IAU since 1964. This represented a major new activity for the Union and was the start of a social revolution, as it represented the time when the IAU began to focus not just on promoting the science of astronomy, but to help people to become astronomers and to promote their careers. It therefore became a more outward-looking people-friendly organization. The move to encompass education continued after 1994 with an active interest to promote the development of astronomy in developing countries. 


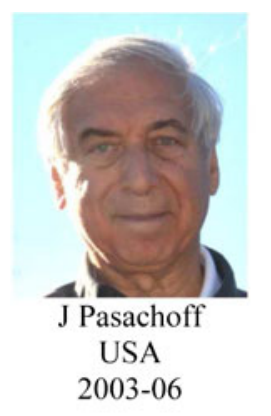

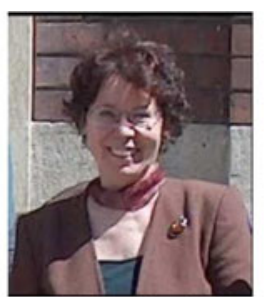

M Stavinschi

Romania

2006-09

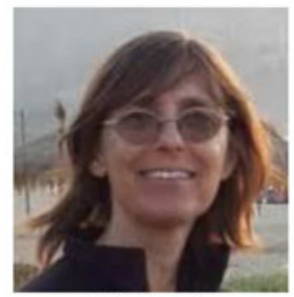

BE García

Argentina

2015-18

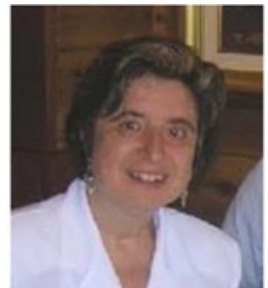

R Ros

Spain

2009-12

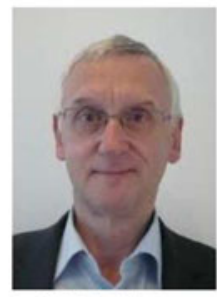

JP de Greve

Belgium

2012-15

Figure 7. C46 (or C.C1) presidents 2003-18.

From 2006 the IAU further branched out to promote astronomy outreach to the public. A new commission for Communicating Astronomy to the Public (C55, which later became C.C2 in 2015) was created in 2006 which promoted this new activity. Also, in 2012 the Office for Astronomy Outreach (OAO) was launched in Tokyo.

In 2015, Division C had four commisions - C1: Astronomy education and development; C2: Communicating astronomy to the public; C3: The history of astronomy and C4: Astronomy and World Heritage. In addition, Commision B7 for the preservation and protection of observatory sites has an affiliation to Division C. This commission combatted light pollution and promoted astro-tourism, yet another new people-oriented activity for the IAU in the 21st century!

In 2015 the Office for Young Astronomers (OYA) was launched in Oslo with the purpose of running and funding the International Schools for Young Astronomers, in conjunction with the Norwegian Academy of Science and Letters (NASL) which has co-sponsored the ISYA.

In 2018 the Office for Astronomy Education (OAE) is to be launched as part of the second IAU Strategic Plan 2020-30.

In the last half century, we have seen the IAU evolve from a purely research-based institution, looking inwards, to an outward-looking organization promoting social change amongst the wider astronomical community, including amateur astronomers, students, young astronomers, the public and star-gazing astro-tourists.

\section{Postscript: the contribution of Edith Alice Müller (1918-95)}

Many people contributed to the fundamental changes in the focus and outlook of the IAU as a result of the work of Commissions 38 and 46. But one of the most important people who initiated these changes was Edith Müller (Fig. 8) from the Geneva Observatory in Switzerland. She was vice-president of Commission 46 from soon after its creation in 1964 (in fact from 1966; initially no vice-president was appointed), and then became C46 president for two triennia, 1967-73. Later, Edith was Vice-President 


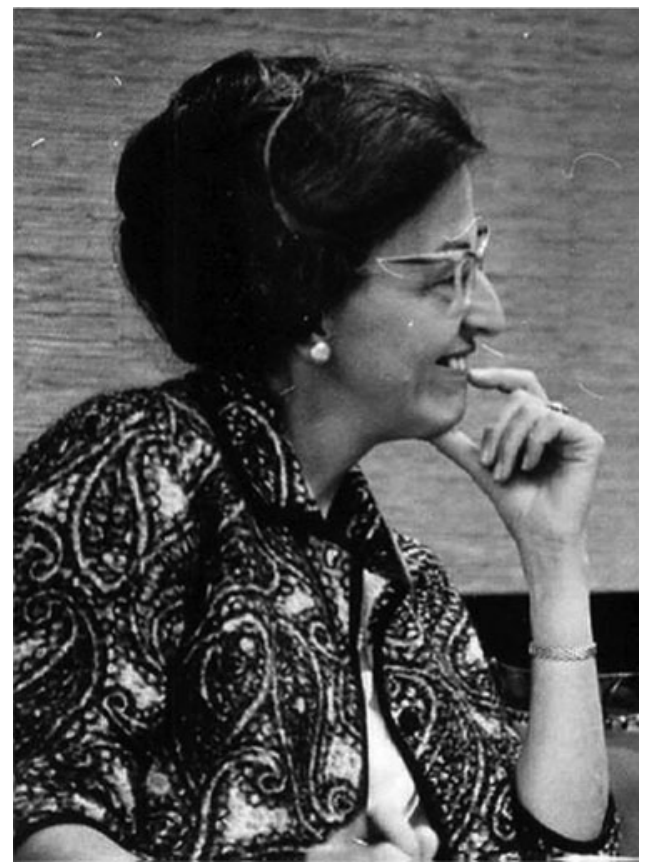

Figure 8. Edith Müller (Switzerland) who served as C38 president, C46 president and IAU General Secretary.

of Commission 38 (1982-85) and then C38 President (1985-88). But between these two commission responsibilities she was IAU General Secretary from 1976 to 1979.

For Commission 46 she initiated the scheme of National Liaisons in each IAU member country, with triennial reports from each National Liaison (at least in principle). The National Liaisons' reports were published in the Commission Newsletter. The National Liaisons were active from August 1973 until August 2015. Edith Müller died in 1995, still actively involved in the IAU until her death.

A memorial volume to Edith Müller was published in 1998 with contributions from many of those who knew her, especially colleagues in Commissions 46 and 38 (Appenzeller, I. et al. 1998). In this volume John Percy wrote: 'Although Edith Müller was not the founding President of Commission 46, she was president for the six crucial years in which the Commission took root, and grew... It is fair to say that, without Edith Müller's time, effort, and thought, the birth and growth of IAU Commission 46 would have been much slower. No one played a more significant role in its evolution that she did (though several individuals come close - Derek McNally and Donat Wentzel are two names which come first to mind)' (Percy 1998).

\section{References}

Appenzeller, I., Chmielewski, Y., Pecker, J.-C., de la Reza, R., Tammann, G. and Wayman P. 1998 Remembering Edith Alice Müller. Astrophysics and Space Science Library 222

Batten, A. H. (ed.) 2001, ASP Conf. Ser.: Astronomy for Developing Countries, pp. xvii +376

L. Gouguenheim, L., McNally, D. and Percy, J.R. (eds.) 1998 New Trends in Astronomy Teaching: IAU Coll. 162, pp. 346, publ. Cambridge Univ. Press

Hearnshaw, J. B. and Martinez, P. 2007, Astronomy for the Developing World, Cambridge Univ. Press, pp. $334+$ xii

Kononovich, E. V. 1979, Trans IAU, 17A, 191-198

McNally, D. 1976, Trans IAU, 16A, 215-217 
McNally, D. 1976, Trans IAU, 16B, 299-305

Minnaert, M. G. J. 1966, Trans IAU, 12B, 629-649

Minnaert, M. G. J. 1970, Trans IAU, 14A, 451-453

Müller, E. A. 1973, Trans IAU, 15A, 559-566

Pasachoff, J. \& Percy, J. 1990, IAU Coll., 105, pp. 445, Cambridge Univ. Press

Percy, J. 1995, Highlights of Astronomy 10, 145-74.

Percy, J. 1996, ASP Conf. Ser. 89, 256

Percy, J. 1998, In Appenzeller I et al. Remembering Edith Alice Müller. Astrophysics and Space Science Library 222, 117-123

Stratton, F. J. M. 1950, Trans IAU, 7, 414-417

Wentzel, D. G. 1982, Trans IAU, 18B, 303-310 